\title{
Model Aturan Klasifikasi Minat Mahasiswa Berwirausaha dengan Algoritma Naive Bayes
}

\author{
Wiwiek Katrina ${ }^{1}$, Agus Perdana Windarto ${ }^{2}$, Dedy Hartama ${ }^{3}$, Saifullah ${ }^{4}$ \\ Sekolah Tinggi Ilmu Komputer (STIKOM) Tunas Bangsa, Indonesia \\ Jl. Jendral Sudirman Blok A No 1-3 Pematangsiantar \\ Email : wiwiekkatrina97@gmail.com, agus.perdana@amiktunasbangsa.ac.id, \\ dedyhartama@amiktunasbangsa.ac.id, saifullah@amiktunasbangsa.ac.id
}

\begin{abstract}
This study aims to determine student interest in entrepreneurship and make entrepreneurship as one of the student activity organizations on campus outside the compulsory subject to create opportunities for a work in the form of innovative ideas. The parameters used in determining student interest in entrepreneurship are social prestige, personal challenges, being a boss, innovation and profit. The data used by giving questionnaires to students of STIKOM Tunas Bangsa Pematangsiantar odd semester. Based on the research that has been done by the author using the Naive Bayes method on student interest in entrepreneurship produces a value of 93.98\%, while the prediction of not interest produces a value of $41.18 \%$. This research is expected to be able to help STIKOM Tunas Bangsa student affairs parties in increasing active student organizations such as entrepreneurship.
\end{abstract}

Keywords: Students, Entrepreneurship, Data Mining, Naive Bayes

Abstrak - Penelitian ini bertujuan untuk mengetahui minat mahasiswa berwirausaha dan menjadikan kewirausahaan sebagai sebagai salah satu organisasi kegiatan mahasiswa di kampus di luar mata kuliah wajib untuk menciptakan peluang sebuah karya berupa ide yang inovatif. Parameter yang digunakan dalam menentukan minat mahasiswa berwirausaha yaitu prestis sosial, tantangan pribadi, menjadi bos, inovasi dan keuntungan. Data yang digunakan dengan memberikan kuesioner kepada mahasiswa STIKOM Tunas Bangsa Pematangsiantar semester ganjil. Berdasarkan penelitian yang telah dilakukan penulis menggunakan metode Naive Bayes pada minat mahasiswa berwirausaha menghasilkan nilai 93,98\% prediksi minat, sedangkan prediksi tidak minat menghasilkan nilai 41,18\%. Penelitian ini diharapkan dapat membantu pihak bagian kemahasiswaan STIKOM Tunas Bangsa dalam meningkatkan mahasiswa aktif berorganisasi seperti berwirausaha.

Kata kunci: Mahasiswa, Berwirausaha, Data Mining, Naive Bayes

\section{PENDAHULUAN}

Indonesia secara umum menghadapi masalah keterbatasan kesempatan kerja, termasuk bagi para lulusan perguruan tinggi dengan semakin meningkatnya jumlah pengangguran intelektual belakangan ini. Agar dapat bersaing dalam persaingan global, lulusan perguruan tinggi dituntut mempunyai kompetensi, keterampilan, profesional yang memadai, sehingga dapat memenangkan persaingan. Oleh karena itu, para lulusan perguruan tinggi/sarjana lulusan perguruan tinggi perlu diarahkan dan didukung untuk tidak hanya berorientasi sebagai pencari kerja (job seeker) namun dapat dan siap menjadi pencipta pekerjaan (job creator). STIKOM Tunas Bangsa merupakan 
salah satu perguruan tinggi swasta yang beralamatkan di Jl. Jendral Sudirman Blok A No. 1,2,3 Pematangsiantar yang bertujuan untuk meningkatkan dan mengembangkan watak dan kepribadian generasi muda yang unggul di bidang ilmu komputer dalam tatanan global dalam rangka usaha mengahadapi revolusi industri 4.0. Permasalahan yang ada saat ini pada STIKOM Tunas Bangsa yaitu kurangnya minat mahasiswa dalam mengikuti kegiatan organisasi yang diadakan Unit Kegiatan Mahasiswa (UKM) di kampus. STIKOM Tunas Bangsa dapat menambahkan organisasi baru agar mahasiswa tertarik dan aktif dalam mengikuti kegiatan organisasi di kampus. Misalnya pendidikan kewirausahaan sebagai salah satu organisasi yang wajib di ikuti. Wirausaha adalah kegiatan menciptakan sesuatu yang baru dan berbeda berupa ide, inovatif dan juga peluang. Sedangkan wirausahawan adalah orang yang melakukan aktivitas wirausaha dicirikan dengan berbakat mengenali produk baru, menentukan cara produksi baru, memasarkannya, serta mengatur permodalan operasinya[1]. Pemahaman kewirausahaan harus dimiliki oleh mahasiswa untuk memotivasi dan mengaktifkan mahasiswa agar lebih berkreasi. Jenis luaran yang dihasilkan dari kegiatan berwirausaha bisa berupa produk atau barang yang dapat dipasarkan untuk menghasilkan keuntungan. Menumbuhkan jiwa kewirausahaan para mahasiswa perguruan tinggi dipercaya merupakan alternatif jalan keluar untuk mengurangi tingkat pengangguran, karena para sarjana diharapkan dapat menjadi wirausahawan muda terdidik yang mampu merintis usahanya sendiri. Dalam rangka mendorong tumbuhnya jiwa kewirausahaan bagi para mahasiswa dan menciptakan lulusan yang mampu menjadi pencipta lapangan kerja (job creator), perlu diadakan pembinaan bagi mahasiswa agar mampu melaksanakan wirausaha (entrepreneur). Ada 2 faktor yang memberikan dorongan kepada seseorang untuk masuk dalam dunia wirausaha, yaitu: Personal Atributes dan Personal Environment. Personal attributes merupakan faktor yang berhubungan dengan aspek kepribadian yang dimiliki seseorang seperti keinginan bebas dalam bekerja dan rasa toleransi terhadap risiko. Sedangkan Personal Environment merupakan faktor dari lingkungan yang memberi dorongan untuk berwirausaha contohnya seperti pendidikan kewirausahaan dapat memberikan dorongan kepada mahasiswa untuk memulai suatu usaha[2]. Berdasarkan penjelasan diatas, peneliti melakukan penelitian dengan menggunakan Data Mining Klasifikasi Naive Bayes untuk mendapatkan hasil penilaian terhadap minat mahasiswa berwirausaha. Metode yang digunakan untuk penyelesaiannya adalah Data Mining Klasifikasi Naive Bayes dengan RapidMinner. Penelitian ini diharapkan dapat membantu pihak bagian kemahasiswaan STIKOM Tunas Bangsa dalam meningkatkan mahasiswa aktif berorganisasi seperti berwirausaha.

\section{METODOLOGI PENELITIAN}

\subsection{Data Mining}

Data mining merupakan kumpulan data dari database berukuran besar yang dirangkum untuk menemukan informasi bermanfaat yang digunakan membantu pengambil keputusan untuk kepentingan sebuah organisasi [3]-[9]. 


\subsection{Klasifikasi}

Klasifikasi merupakan proses untuk menemukan model dengan tujuan memperkirakan kelas dari suatu objek yang labelnya tidak diketahui. Pada proses klasifikasi data yang diinputkan adalah data record atau data sampel [10].

\subsection{Naive Bayes}

Naive Bayes merupakan metode probabilistic pengklasifikasian sederhana berdasarkan Teorema Bayes dimana pengklasifikasian dilakukan melalui training set sejumlah data secara efisien. Naive bayes mengasumsikan bahwa nilai dari sebuah input atribut pada kelas yang diberikan tidak tergantung dengan nilai atribut yang lain. Teorema Bayes sendiri dikemukakan oleh ilmuwan Inggris Thomas Bayes, yaitu memprediksi peluang di masa depan berdasarkan pengalaman di masa sebelumnya sehingga dikenal sebagai Teorema Bayes[11]. Untuk menyelesaikan metode Naive Bayes dapat dilakukan dengan persamaanpersamaan sebagai berikut:

$$
P(H \mid X)=\frac{P(X \mid H) *(P(H)}{P(X)}
$$

Dimana:

X : Data dengan class yang belum diketahui

$\mathrm{H} \quad$ : Hipotesis data merupakan suatu class spesifik

$\mathrm{P}(\mathrm{H} \mid \mathrm{X})$ : Probabilitas hipotesis $\mathrm{H}$ berdasarkan kondisi $\mathrm{X}$ (posteriori probabilitas)

$\mathrm{P}(\mathrm{H})$ : Probabilitas hipotesis $\mathrm{H}$ (prior probabilitas)

$\mathrm{P}(\mathrm{X} \mid \mathrm{H})$ : Probabilitas X berdasarkan kondisi pada hipotesis $\mathrm{H}$

$\mathrm{P}(\mathrm{X})$ : Probabilitas $\mathrm{X}$

Penjabaran lebih lanjut rumus Naive Bayes tersebut dilakukan dengan menjabarkan secara terperinci $\left(\mathrm{C} \mid \mathrm{X}_{1} \ldots, \mathrm{X}_{\mathrm{n}}\right)$ menggunakan aturan perkalian sebagai berikut.

$$
\begin{aligned}
& \mathrm{P}\left(\mathrm{C} \mid \mathrm{x}_{1}, \ldots \ldots, \mathrm{X}_{\mathrm{n}}=\mathrm{P}(\mathrm{C}) \mathrm{P}\left(\mathrm{x}_{1}, \ldots . ., \mathrm{x}_{\mathrm{n}} \mid \mathrm{C}\right)\right. \\
&=\mathrm{P}(\mathrm{C}) \mathrm{P}\left(\mathrm{X}_{1} \mid \mathrm{C}\right) \mathrm{P}\left(\mathrm{X}_{2}, \ldots ., \mathrm{X}_{\mathrm{n}} \mid \mathrm{C}, \mathrm{X}_{1}\right) \\
&=(\mathrm{C}) \mathrm{P}\left(\mathrm{X}_{1} \mid \mathrm{C}\right) \mathrm{P}\left(\mathrm{X}_{2} \mid \mathrm{C}, \mathrm{X}_{1}\right) \mathrm{P}\left(\mathrm{X}_{3}, \ldots \mathrm{X}_{\mathrm{n}} \mid \mathrm{C}, \mathrm{X}_{1}, \mathrm{X}_{2}(\mathrm{C}) \mathrm{P}\left(\mathrm{X}_{1} \mid \mathrm{C}\right)\right. \\
& \mathrm{P}\left(\mathrm{X}_{2} \mid \mathrm{C}, \mathrm{X}_{1}\right) \mathrm{P}\left(\mathrm{X}_{3} \mid \mathrm{C}, \mathrm{X}_{1}, \mathrm{X}_{2}\right) \mathrm{P}\left(\mathrm{X}_{4}, \ldots, \mathrm{X}_{\mathrm{n}} \mid \mathrm{C}, \mathrm{X}_{1}, \mathrm{X}_{2}, \mathrm{X}_{3}\right) \mathrm{P}(\mathrm{C}) \\
&= \mathrm{P}\left(\mathrm{X}_{1} \mid \mathrm{C}\right) \mathrm{P}\left(\mathrm{X}_{2} \mid \mathrm{C}, \mathrm{X}_{1}\right) \mathrm{P}\left(\mathrm{X}_{3} \mid \mathrm{C}, \mathrm{X}_{1}, \mathrm{X}_{2}\right) \ldots \\
& \mathrm{P}\left(\mathrm{X}_{\mathrm{n}} \mid \mathrm{C}, \mathrm{X}_{1}, \mathrm{X}_{2}, \mathrm{X}_{3}, \ldots . . \mathrm{X}_{\mathrm{n}-1} \ldots . .\right.
\end{aligned}
$$

Semakin banyak faktor-faktor yang semakin kompleks berpengaruh terhadap nilai probabilitas, maka semakin tidak mungkin untuk menghitung nilai tersebut satu persatu. Dengan asumsi tersebut, diperlukan persamaan (3) :

$$
\begin{aligned}
& P\left(X_{i} \mid X_{j}=\frac{P\left(X_{i}\right) p\left(x_{j}\right)}{P\left(x_{j}\right)}=\frac{P\left(X_{i} \cap X_{j}\right.}{P\left(x_{j}\right)}=P\left(X_{i}\right)\right. \\
& \text { Untuk } \mathrm{i} \neq \mathrm{j}, \text { sehingga } \\
& \quad P\left(X_{i} \mid C_{y} X_{j}=P\left(X_{i} \mid C\right)\right.
\end{aligned}
$$


Dari persamaan (4) tersebut dapat di ambil kesimpulan bahwa asumsi independensi membuat syarat perhitungan menjadi lebih sederhana. Selanjutnya penjabaran $(P(C / X 1, \ldots . ., X n)$ dapat disederhanakan menjadi persamaan (5) :

$$
P(X 2 \mid C) P(X 3 \mid C) \ldots P\left(C \mid X 1_{, \ldots} X n\right)=P(X 1 \mid C)=\prod_{i=1}^{n} P\left(X_{i} \mid C\right)
$$

Keterangan:

$\prod_{i=1}^{n} P\left(X_{i} \mid C\right)=$ perkalian ranting antar atribut.

Persamaan (5) merupakan teorema Bayes yang kemudian akan digunakan untuk melakukan perhitungan klasifikasi. Untuk klasifikasi dengan data continue atau data angka menggunakan rumus distribusi Gaussian dengan 2 parameter : mean $\mu$ dan varian $\sigma$ :

$$
p\left(X_{i}=X_{i} \mid C=c_{j}\right)=\frac{1}{\sqrt{2 \pi \sigma i j}} \exp \frac{(x i-\mu i j) 2}{2 \sigma 2 i j}
$$

Dimana :

$P$ : Peluang

$\mathrm{X}_{\mathrm{i}}$ : Atribut ke i

$\mathrm{X}_{\mathrm{j}}$ : Nilai atribut ke $\mathrm{i}$

$\mathrm{C}$ : Kelas yang dicari

$\mathrm{C}_{\mathrm{i}}$ : Sub kelas Y yang dicari

$\mu$ : Menyatakan rata-rata dari seluruh atribut

$\sigma$ : Deviasi standar, menyatakan varian dari seluruh atribut.

Dalam metode Naive Bayes diperlukan data latih dan data uji yang ingin diklasifikasikan, dalam Naive Bayes, semakin banyak data latih yang yang dilibatkan, semakin baik hasil yang prediksi yang diberikan.Menghitung $\mathrm{P}\left(\mathrm{C}_{\mathrm{i}}\right)$ yang merupakan probabilitas prior untuk setiap sub kelas $\mathrm{C}$ yang akan dihasilkan menggunakan persamaan:

$$
P(c i)=\frac{s i}{s}
$$

Dimana Si adalah jumlah data training dari kategori $\mathrm{Ci}$, dan s adalah jumlah total data training. Menghitung $\mathrm{P}\left(\mathrm{X}_{\mathrm{i}} \mid \mathrm{C}_{\mathrm{i}}\right)$ yang merupakan probabilitas posterior Xi dengan syarat $C$ menggunakan persamaan (5).

\subsection{Minat Berwirausaha}

Minat berwirausaha adalah kemampuan untuk mendorong diri sendiri dan berbuat sesuatu untuk memenuhi kebutuhan hidup serta pemecahan permasalahan hidup, memajukan usaha atau menciptakan usaha baru dengan perasaan senang karena membawa manfaat bagi dirinya untuk berusaha memenuhi kebutuhan hidupnya tanpa merasa takut akan resiko yang akan 
dihadapi, senantiasa belajar dari kegagalan yang dialami, serta mengembangkan usaha yang diciptakannya[12].

\section{HASIL DAN PEMBAHASAN}

\subsection{Baca Data Training}

Data yang digunakan dalam penelitian ini adalah berupa wawancara yang dilakukan kepada mahasiswa STIKOM Tunas Bangsa semester ganjil dan memberikan pertanyaan yang dituangkan dalam kuesioner sebanyak 150 data. Adapun kriteria yang digunakan yaitu yaitu prestis sosial, tantangan pribadi, menjadi bos, inovasi, keuntungan.

Tabel 1. Data Training

\begin{tabular}{|c|c|c|c|c|c|c|}
\hline Alternatif & $\begin{array}{c}\text { Prestis } \\
\text { Sosial } \\
\end{array}$ & $\begin{array}{c}\text { Tantangan } \\
\text { Pribadi }\end{array}$ & $\begin{array}{c}\text { Menjadi } \\
\text { Bos }\end{array}$ & Inovasi & Keuntungan & $\begin{array}{c}\text { Tanggapan } \\
\text { Akhir }\end{array}$ \\
\hline A1 & $\mathrm{S}$ & $\mathrm{SS}$ & $\mathrm{S}$ & SS & $\mathrm{S}$ & Minat \\
\hline $\mathrm{A} 2$ & $\mathrm{~S}$ & SS & $\mathrm{S}$ & $\mathrm{S}$ & $\mathrm{S}$ & Minat \\
\hline A3 & $\mathrm{S}$ & SS & SS & SS & $\mathrm{S}$ & Minat \\
\hline A4 & SS & SS & SS & SS & SS & Minat \\
\hline A5 & SS & SS & SS & SS & SS & Minat \\
\hline A6 & $S$ & SS & SS & SS & SS & Minat \\
\hline A7 & $\mathrm{S}$ & $\mathrm{S}$ & $\mathrm{C}$ & $\mathrm{S}$ & $\mathrm{S}$ & Tidak Minat \\
\hline A8 & $\mathrm{C}$ & SS & SS & $\mathrm{C}$ & $\mathrm{S}$ & Minat \\
\hline A9 & SS & $\mathrm{S}$ & SS & $\mathrm{S}$ & SS & Minat \\
\hline A10 & $\mathrm{S}$ & $\mathrm{S}$ & SS & $\mathrm{S}$ & $S$ & Minat \\
\hline A11 & $\mathrm{S}$ & $\mathrm{S}$ & $\mathrm{S}$ & $\mathrm{S}$ & SS & Minat \\
\hline A12 & $\mathrm{S}$ & SS & SS & SS & SS & Minat \\
\hline A13 & $S$ & $S$ & SS & SS & SS & Minat \\
\hline A14 & $\mathrm{S}$ & $\mathrm{S}$ & SS & $\mathrm{S}$ & $S$ & Minat \\
\hline A15 & SS & $\mathrm{S}$ & $S$ & $S$ & $S$ & Minat \\
\hline A141 & SS & $\mathrm{S}$ & $\mathrm{S}$ & $\mathrm{S}$ & $\mathrm{S}$ & $? ?$ \\
\hline A142 & $\mathrm{S}$ & $\mathrm{S}$ & SS & $\mathrm{S}$ & $\mathrm{S}$ & Minat \\
\hline A143 & $\mathrm{S}$ & SS & SS & $\mathrm{S}$ & $\mathrm{S}$ & Minat \\
\hline A144 & $\mathrm{C}$ & $\mathrm{S}$ & $\mathrm{S}$ & $\mathrm{C}$ & $\mathrm{S}$ & Minat \\
\hline A145 & $\mathrm{C}$ & $S$ & $S$ & $S$ & $S$ & Minat \\
\hline A146 & $\mathrm{C}$ & $\mathrm{S}$ & $\mathrm{C}$ & $\mathrm{S}$ & $\mathrm{S}$ & Minat \\
\hline A147 & $\mathrm{C}$ & $\mathrm{S}$ & $\mathrm{S}$ & $\mathrm{S}$ & $\mathrm{C}$ & Tidak Minat \\
\hline A148 & $\mathrm{S}$ & TS & TS & $\mathrm{C}$ & $S$ & Tidak Minat \\
\hline A149 & $\mathrm{C}$ & $\mathrm{C}$ & $\mathrm{S}$ & $\mathrm{S}$ & $\mathrm{C}$ & Tidak Minat \\
\hline A150 & $\mathrm{C}$ & $\mathrm{S}$ & $\mathrm{C}$ & $\mathrm{C}$ & $\mathrm{C}$ & Tidak Minat \\
\hline
\end{tabular}

Sumber: STIKOM Tunas Bangsa Pematangsiantar

Dalam menentukan probabilitas setiap kriteria, penulis menghitung bagianbagian yang terdapat pada setiap kriteria, setiap kriteria menggunakan skala linker 4 yaitu SS (Sangat Setuju), S (Setuju), C (Cukup), dan TS (Tidak Setuju). Untuk menghitung probabilitas kemungkinan dari kriteria prestis sosial dan tantangan pribadi dapat dilihat pada tabel 2 dan tabel 3 : 
Tabel 2. Probabilitas Kriteria Prestis Sosial

\begin{tabular}{|c|c|c|c|c|}
\hline \multirow{3}{*}{$\begin{array}{c}\text { Prestis } \\
\text { Sosial }\end{array}$} & \multicolumn{2}{|c|}{$\begin{array}{c}\text { Jumlah } \\
\text { Kejadian } \\
\text { Dipilih }\end{array}$} & \multicolumn{2}{|c|}{ Probabilitas } \\
\cline { 2 - 5 } Minat & $\begin{array}{c}\text { Tidak } \\
\text { Minat }\end{array}$ & Minat & $\begin{array}{c}\text { Tidak } \\
\text { Minat }\end{array}$ \\
\hline SS & 49 & 1 & 0,360 & 0,071 \\
\hline S & 73 & 7 & 0,537 & 0,500 \\
\hline C & 14 & 6 & 0,103 & 0,429 \\
\hline TS & 0 & 0 & 0,000 & 0,000 \\
\hline Jumlah & 136 & 14 & 1 & 1 \\
\hline
\end{tabular}

Tabel 3. Probabilitas Kriteria Tantangan Pribadi

\begin{tabular}{|c|c|c|c|c|}
\hline \multirow{2}{*}{$\begin{array}{c}\text { Tantangan } \\
\text { Pribadi }\end{array}$} & \multicolumn{2}{|c|}{$\begin{array}{c}\text { Jumlah } \\
\text { Kejadian } \\
\text { Dipilih }\end{array}$} & \multicolumn{2}{|c|}{ Probabilitas } \\
\cline { 2 - 5 } & Minat & $\begin{array}{c}\text { Tidak } \\
\text { Minat }\end{array}$ & Minat & $\begin{array}{c}\text { Tidak } \\
\text { Minat }\end{array}$ \\
\hline SS & 55 & 3 & 0,404 & 0,214 \\
\hline S & 71 & 8 & 0,522 & 0,571 \\
\hline C & 10 & 2 & 0,074 & 0,143 \\
\hline TS & 0 & 1 & 0,000 & 0,071 \\
\hline Jumlah & 136 & 14 & 1 & 1 \\
\hline
\end{tabular}

Untuk menghitung probabilitas kemungkinan dari kriteria menjadi bos dan inovasi dapat dilihat pada tabel 4 dan tabel 5 :

Tabel 4 . Probabilitas Kriteria Menjadi Bos

\begin{tabular}{|c|c|c|c|c|}
\hline $\begin{array}{c}\text { Menjadi } \\
\text { Bos }\end{array}$ & \multicolumn{2}{|c|}{$\begin{array}{c}\text { Jumlah } \\
\text { Kejadian } \\
\text { Dipilih }\end{array}$} & \multicolumn{2}{|c|}{ Probabilitas } \\
\cline { 2 - 5 } & Minat & $\begin{array}{c}\text { Tidak } \\
\text { Minat }\end{array}$ & Minat & $\begin{array}{c}\text { Tidak } \\
\text { Minat }\end{array}$ \\
\hline SS & 84 & 1 & 0,618 & 0,071 \\
\hline S & 46 & 6 & 0,338 & 0,429 \\
\hline C & 6 & 6 & 0,044 & 0,429 \\
\hline TS & 0 & 1 & 0,000 & 0,071 \\
\hline Jumlah & 136 & 14 & 1 & 1 \\
\hline
\end{tabular}

Tabel 5. Probabilitas Kriteria Inovasi

\begin{tabular}{|c|c|c|c|c|}
\hline Inovasi & \multicolumn{2}{|c|}{$\begin{array}{c}\text { Jumlah } \\
\text { Kejadian } \\
\text { Dipilih }\end{array}$} & \multicolumn{2}{|c|}{ Probabilitas } \\
\cline { 2 - 5 } & Minat & $\begin{array}{c}\text { Tidak } \\
\text { Minat }\end{array}$ & Minat & $\begin{array}{c}\text { Tidak } \\
\text { Minat }\end{array}$ \\
\hline SS & 56 & 5 & 0,412 & 0,357 \\
\hline S & 61 & 5 & 0,449 & 0,357 \\
\hline C & 19 & 4 & 0,140 & 0,286 \\
\hline TS & 0 & 0 & 0,000 & 0,000 \\
\hline Jumlah & 136 & 14 & 1 & 1 \\
\hline
\end{tabular}


Untuk menghitung probabilitas kemungkinan dari kriteria keuntungan dapat dilihat pada tabel 6 :

Tabel 6. Probabilitas Kriteria Keuntungan

\begin{tabular}{|c|c|c|c|c|}
\hline \multirow{2}{*}{ Keuntungan } & \multicolumn{2}{|c|}{$\begin{array}{c}\text { Jumlah } \\
\text { Kejadian } \\
\text { Dipilih }\end{array}$} & \multicolumn{2}{c|}{ Probabilitas } \\
\cline { 2 - 5 } & Minat & $\begin{array}{c}\text { Tidak } \\
\text { Minat }\end{array}$ & Minat & $\begin{array}{c}\text { Tidak } \\
\text { Minat }\end{array}$ \\
\hline SS & 71 & 3 & 0,522 & 0,214 \\
\hline S & 57 & 4 & 0,419 & 0,286 \\
\hline C & 8 & 7 & 0,059 & 0,500 \\
\hline TS & 0 & 0 & 0,000 & 0,000 \\
\hline Jumlah & 136 & 14 & 1 & 1 \\
\hline
\end{tabular}

\subsection{Perhitungan Probabilitas Prior (P(Ci))}

Dari 150 data latih yang digunakan, diketahui kelas minat sebanyak 136 data, dan kelas tidak minat sebanyak 14 data. Perhitungan probabilitas prior kemungkinan minat dalam menentukan minat mahasiswa dalam berwirausaha, yaitu :

$$
\begin{aligned}
P(H \mid X) & =\frac{(P(H)}{P(X)} \\
& =\frac{136}{150} \\
& =0,906
\end{aligned}
$$

Sedangkan perhitungan probabilitas tidak minat yaitu :

$$
\begin{aligned}
P(H \mid X) & =\frac{(P(H)}{P(X)} \\
& =\frac{14}{150} \\
& =0,093
\end{aligned}
$$

\subsection{Perhitungan Manual}

Berdasarkan data training pada tabel 1. untuk menghitung nilai minat pada data responden 141 adalah sebagai berikut.

$\mathrm{P}(141 \mid$ Minat $)=\mathrm{P}($ Prestis Sosial $=\mathrm{SS} \mid$ Minat $) \times \mathrm{P}($ Tantangan Pribadi $=\mathrm{S} \mid$ Minat $) \times \mathrm{P}($ Menjadi Bos $=\mathrm{S} \mid$ Minat $) \times \mathrm{P}($ Inovasi $=\mathrm{S} \mid$ Minat $) \times \mathrm{P}($ Keuntungan $=\mathrm{S} \mid$ Minat $)$

$=0,360 \times 0,522 \times 0,338 \times 0,449 \times 0,419$

$=0,012$

Sedangkan untuk menghitung nilai Tidak Minat pada data responden 141 sebagai berikut :

$\mathrm{P}(141 \mid$ Tidak Minat $)=\mathrm{P}($ Prestis Sosial $=$ SS | Tidak Minat $) \times \mathrm{P}($ Tantangan Pribadi $=\mathrm{S} \mid$ Tidak Minat $) \times \mathrm{P}($ Menjadi Bos $=\mathrm{S} \mid$ Tidak Minat $) \times \mathrm{P}($ Inovasi $=\mathrm{S}$ $\mid$ Tidak Minat) $\mathrm{x}$ P(Keuntungan $=\mathrm{S} \mid$ Tidak Minat $)$ 
$=0,071 \times 0,571 \times 0,429 \times 0,357 \times 0,286$

$=0,002$

Perhitungan data responden 141 untuk menghitung pemaksimalan nilai Minat yaitu :

$$
\begin{aligned}
\mathrm{P}(\text { Minat } \mid \mathrm{C}) & =\mathrm{P}(\mathrm{Rn} \mid \mathrm{C}) * \mathrm{P}(\text { Minat }) \\
& =\mathrm{P}(141 \mid \mathrm{C}) * \mathrm{P}(\text { Minat }) \\
& =0,012 \times 0,906 \\
& =0,010
\end{aligned}
$$

Sedangkan perhitungan maksimal nilai Tidak Minat pada data responden 141 yaitu :

$$
\begin{aligned}
\mathrm{P}(\text { Tidak Minat } \mid \mathrm{C}) & =\mathrm{P}(\mathrm{Rn} \mid \mathrm{C}) * \mathrm{P}(\text { Tidak Minat }) \\
& =\mathrm{P}(141 \mid \mathrm{C}) * \mathrm{P}(\text { Tidak Minat }) \\
& =0,002 \times 0,093 \\
& =0
\end{aligned}
$$

Pada data responden 141 diketahui perhitungan maksimal kelas Minat = 0,010 , kelas tidak Minat $=0$. sehingga $0,010>0$. Dapat dikatakan data responden 141 data responden yang Minat berwirausaha.

\subsection{Proses Training dan Testing}

Proses training yaitu melakukan proses pelatihan data pada model (Naive Bayes). Sedangkan proses testing yaitu melakukan pengujian data yang akan menghasilkan grafik atau pola. Pada gambar 1 dijelaskan bahwa proses training digunakan untuk blok model Naive Bayes, dihubungkan dengan garis penghubung pada blok apply model dan blok performance dengan bagian testing sebagai penampil informasi hasil dari pengujian data, hasil pengujian ini akan menghasilkan arsitektur Naive Bayes.

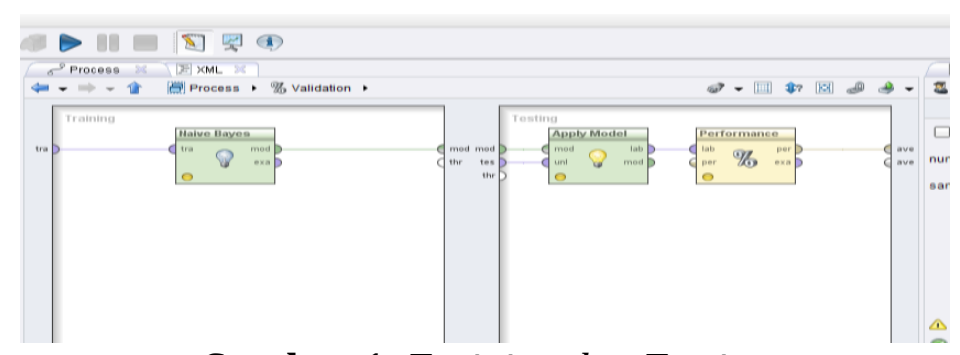

Gambar 1. Training dan Testing

\subsection{Hasil Klasifikasi Class dengan Metode Naive Bayes}

Hasil klasifikasi dari data minat mahasiswa berwirausaha dengan metode Naive Bayes membagi 2 kelas klasifikasi yaitu class minat dan class tidak minat. Untuk nilai class minat yaitu 0.900 dan nilai class tidak minat yaitu 0.093 , dapat dilihat pada gambar 2 sebagai berikut : 


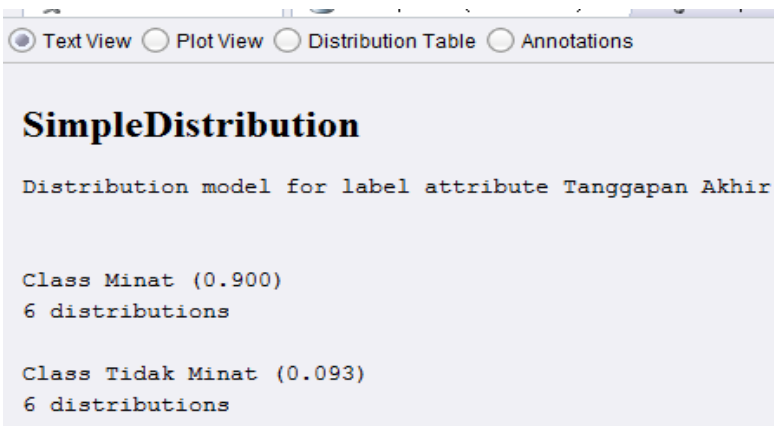

\section{Gambar 2. Simple Distribution Model}

\section{KESIMPULAN}

Dengan demikian dari hasil penelitian, pembahasan dan pengujian model dapat disimpulkan bahwa :

a. Nilai accuracy $88.00 \%$, untuk nilai precision yaitu $92.59 \%$ pada class minat dan $50.00 \%$ pada class tidak minat, sedangkan nilai recall $93.98 \%$ pada class minat dan $41.18 \%$ untuk nilai class tidak minat.

b. Hasil klasifikasi dari data minat mahasiswa berwirausaha dengan metode Naive Bayes untuk nilai class minat yaitu 0.900 dan nilai class tidak minat yaitu 0.093. Penerapan data mining dalam menentukan klasifikasi minat mahasiswa berwirausaha dapat digunakan untuk memprediksi minat dan tidak minat mahasiswa berwirausaha dengan algoritma Naive Bayes kemudian data diuji menggunakan software Rapidminer.

\section{DAFTAR PUSTAKA}

[1] G. D. Rembulan and F. Fensi, "Pengaruh Pendidikan Kewirausahaan Terhadap Minat Berwirausaha," Jurnal Pengabdian dan Kewirausahaan, vol. 1, no. 1, pp. 65-73, 2016.

[2] A. A. G. M. Suarjana and L. M. Wahyuni, "Faktor Penentu Minat Berwirausaha Mahasiswa (Suatu Evaluasi Pembelajaran)," Jurnal Bisnis dan Kewirausahaan, vol. 13, no. 1, pp. 11-22, 2017.

[3] I. Parlina, A. P. Windarto, A. Wanto, and M. R. Lubis, "Memanfaatkan Algoritma K-Means dalam Menentukan Pegawai yang Layak Mengikuti Asessment Center untuk Clustering Program SDP," CESS (Journal of Computer Engineering System and Science), vol. 3, no. 1, pp. 87-93, 2018.

[4] R. W. Sari, A. Wanto, and A. P. Windarto, "Implementasi Rapidminer dengan Metode KMeans (Study Kasus: Imunisasi Campak pada Balita Berdasarkan Provinsi)," KOMIK (Konferensi Nasional Teknologi Informasi dan Komputer), vol. 2, no. 1, pp. 224-230, 2018.

[5] S. Sudirman, A. P. Windarto, and A. Wanto, "Data Mining Tools | RapidMiner: K-Means Method on Clustering of Rice Crops by Province as Efforts to Stabilize Food Crops In Indonesia," IOP Conference Series: Materials Science and Engineering, vol. 420, no. 12089, pp. 1-8, 2018.

[6] A. P. Windarto, "Implementation of Data Mining on Rice Imports by Major Country of Origin Using Algorithm Using K-Means Clustering Method," International Journal of artificial intelligence research, vol. 1, no. 2, pp. 26-33, 2017.

[7] A. P. Windarto, "Penerapan Data Mining Pada Ekspor Buah-Buahan Menurut Negara Tujuan Menggunakan K-Means Clustering," Techno.COM, vol. 16, no. 4, pp. 348-357, 2017.

[8] M. G. Sadewo, A. P. Windarto, and A. Wanto, "Penerapan Algoritma Clustering dalam Mengelompokkan Banyaknya Desa/Kelurahan Menurut Upaya Antisipasi/ Mitigasi Bencana Alam Menurut Provinsi dengan K-Means," KOMIK (Konferensi Nasional Teknologi Informasi dan Komputer), vol. 2, no. 1, pp. 311-319, 2018. 
[9] M. G. Sadewo, A. P. Windarto, and D. Hartama, "Penerapan Datamining Pada Populasi Daging Ayam Ras Pedaging Di Indonesia Berdasarkan Provinsi Menggunakan K-Means," InfoTekJar (Jurnal Nasional Informatika dan Teknologi Jaringan), vol. 2, no. 1, pp. 60-67, 2017.

[10] A. Nugroho and Subhanar, "Klasifikasi Naïve Bayes untuk Prediksi Kelahiran pada Data Ibu Hamil," Berkala MIPA, vol. 23, no. September, pp. 297-308, 2013.

[11] D. Dahri, F. Agus, and D. M. Khairina, "METODE NAIVE BAYES UNTUK PENENTUAN PENERIMA BEASISWA BIDIKMISI UNIVERSITAS MULAWARMAN," Jurnal Informatika Mulawarman, vol. 11, no. 2, 2016.

[12] J. S. Hendrawan and H. Sirine, "Pengaruh Sikap Mandiri, Motivasi, Pengetahuan Kewirausahaan Terhadap Minat Berwirausaha (Studi Kasus pada Mahasiswa FEB UKSW Konsentrasi Kewirausahaan)," Asian Journal of Innovation and Entrepreneurship, vol. 2, no. 3, pp. 291-314, 2017. 